

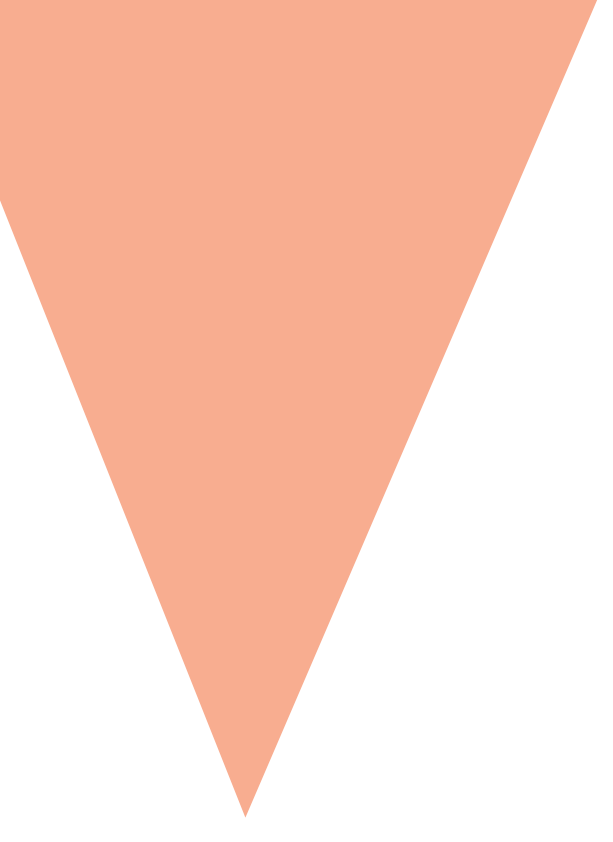

\title{
Gestão de carreiras criativas: \\ passado e futuro da pesquisa acadêmica
}

\author{
Roberto Guanabara Calasans ${ }^{1}$ \\ Eduardo Paes Barreto Davel ${ }^{2}$
}

1 Mestre em Administração pela Universidade Federal da Bahia. Professor do Instituto Federal de Educação, Ciência e Tecnologia da Bahia. E-mail: roberto.calasans@gmail.com.

2 Pós-doutorado em Administração pela Nova School of Business and Economics da Universidade Nova de Lisboa (Portugal). Ph.D. em Administração pela École des Hautes Études commerciales de Montreal (Canadá). Professor na Escola de Administração da Universidade Federal da Bahia. E-mail: davel.eduardo@gmail.com. 


\section{RESUMO}

Os estudos sobre gestão de carreira evoluíram muito em conteúdo, métodos e teorias, mas o principal foco permaneceu na análise da carreira, somente tangenciando as questões de gestão. A produção acadêmica em carreiras criativas ainda é discreta, fragmentada e frágil sobre aspectos de gestão. Essa pesquisa buscou revisar e integrar a produção acadêmica sobre gestão de carreiras no contexto do trabalho criativo. Para isso, foi feita uma revisão das pesquisas acadêmicas publicadas, nacional e internacionalmente, delimitando as principais teorias e dimensões. A análise do material pesquisado permitiu o desenvolvimento de quatro perspectivas para os estudos nesse campo: axiológica, tecnológica, coletiva e social. Os resultados desta análise contribuem para (1) uma melhor compreensão das dimensões de gestão da carreira criativa; (2) a identificação de desafios para estudos sobre esse tema; e (3) uma discussão de orientações para pesquisas futuras.

Palavras-chave: Gestão de carreiras. Carreiras criativas. Carreira artística. Identidade.

\section{ABSTRACT}

Career management studies have evolved in terms of contents, methods and theories, but its main focus still lies on career analysis and not on its management. Academic production on creative careers is still discrete, fragmented and even more fragile in terms of management. This study reviews and integrates academic production on career management in the field of creative work. Thus, a literature review was conducted on the basis of research nationally and internationally published to identify the main theories and dimensions. For such, we developed four perspectives for the studies in this field of knowledge: axiological, technological, collective and social. Results from that analysis produce (a) a better understanding of the dimensions of creative career management, (b) the identification of challenges for studies on this topic, and (c) a discussion on the guidelines for future research.

Keywords: Career management. Creative career. Artistic career. Identity. 


\section{INTRODUÇÃO}

gestão de carreiras é um campo de estudos que se desenvolveu com maior força a partir da segunda metade da década de 1970 e tem evoluído constantemente ao longo desses anos. Partindo de um contexto em que a principal preocupação era o seu desenvolvimento dentro das organizações, as teorias sobre carreiras focaram nos principais componentes da carreira e na integração entre os objetivos do indivíduo e da organização (KILIMNIK; VISENTIN, 2014). Com o passar dos anos e o aumento da quantidade de estudos no campo das carreiras, houve mais dispersão. Ocorreu uma migração de temáticas focadas na relação entre o indivíduo e a organização para a análise de fatores pessoais, mais voltados para a vida profissional de uma pessoa ao longo da sua trajetória de vida (ARTHUR; HALL; LAWRENCE, 1989). Dessa mudança de direção surgiram diversas teorias e conteúdos que guiaram os estudos em carreira ao longo dos últimos vinte anos, como as teorias da carreira proteana, sem fronteiras e multidirecionais. Outros temas relevantes são as transições, as âncoras e as metáforas que, dentre outros assuntos, analisam e descrevem os processos e características de uma carreira. 
Apesar de toda a evolução em quantidade e temáticas de pesquisa no campo das carreiras, é possível perceber um foco muito mais voltado para a carreira como teoria, seus conceitos, elementos e características. Dessa maneira, identifica-se uma escassez de estudos que analisem os processos e possibilidades de sua gestão, campo que surge como passível de novas contribuições acadêmicas e práticas. Ou seja, o enfoque na gestão da carreira é limitado e quando poucas pesquisas o abordam, o que é considerado de forma implícita é a gestão da carreira de trabalhadores de uma organização feita pela própria área gestão de pessoas da empresa, num contexto em que as pessoas passavam grande parte da vida em uma organização. Mergulhadas no setor artístico e na economia criativa, muitas carreiras não seguem os padrões tradicionais previstos pela maioria das pesquisas em carreiras. As pesquisas que estudam as carreiras criativas ainda revelam uma fragmentação de temáticas e abordagens. Com efeito, a construção de teorias no campo de pesquisa em carreiras criativas é discreta e pulverizada, com determinado desencontro de abordagens. Aproveitando-se das pesquisas já existentes no campo de carreiras, os trabalhos que analisam as trajetórias artísticas ainda enfocam, principalmente, os processos de carreira e não as dinâmicas de sua gestão.

O objetivo desta pesquisa é revisar e integrar a produção acadêmica sobre gestão de carreiras no contexto do trabalho criativo. Para isso foi necessário mapear, selecionar e analisar os principais trabalhos no campo da carreira e de gestão da carreira, relacionando-os com os estudos sobre carreiras criativas. Dessa maneira, há um entendimento dos diversos caminhos que esse campo de pesquisa seguiu no seu desenvolvimento, os impactos que proporcionou nas pesquisas sobre carreiras criativas. Em grande parte do estudo, as pesquisas associam carreiras criativas a carreiras artísticas. Então, criatividade e arte estarão conectados em muitos momentos.

O método utilizado foi o mapeamento, a seleção e a análise das pesquisas existentes e publicadas, nacional e internacionalmente, 
que tratam do tema da carreira, da gestão da carreira e da carreira criativa. As buscas foram realizadas nas bases da Sage Publications Journal, Academy of Management, Emerald Insight, Routledge, Periódicos CAPES e Spell. Livros também foram pesquisados nas bases da Amazon, da Estante Virtual e da Library of Congress (Estados Unidos). Foram utilizadas as seguintes palavras-chave: carreira, carreira criativa, indústria cultural, indústria criativa, carreira artística e seus equivalentes na língua inglesa. A partir dessas pesquisas foram selecionados os textos que, após leitura do título e do resumo, apresentaram maior relevância para o alcance dos objetivos propostos por este estudo. Os resultados desta pesquisa delimitam algumas lacunas existentes no campo de estudos sobre gestão de carreiras criativas, apontando para perspectivas futuras da pesquisa acadêmica nesse campo.

\section{GESTÃO DE CARREIRAS: PRINCIPAIS DISCUSSÕES}

O termo "carreira" é usado para descrever as experiências de trabalho que uma pessoa desenvolve ao longo da sua vida profissional. O termo carrega múltiplas interpretações e implicações para os indivíduos (ADAMSON; DOHERTY; VINEY, 1998; COLLIN, 2007). Apesar de existirem registros de trabalhos sobre carreiras desde 1937, somente a partir da segunda metade da década de 1970 estabeleceu-se um campo de pesquisa sobre carreiras na área de administração em âmbito internacional (KILIMNIK; VISENTIN, 2014). Esses trabalhos analisaram os componentes das carreiras e a sua ligação com as organizações, através da integração de objetivos individuais e organizacionais.

Na sequência, as carreiras foram estudadas sob diversos aspectos. Para a análise de carreiras foram desenvolvidas teorias e diferentes dimensões foram discutidas. Dentre as principais teorias discutidas, destacam-se: (1) as carreiras tradicionais, que relacionam a trajetória profissional à ascensão hierárquica em uma organização (ALVES, 2012); (2) as carreiras sem fronteiras, caracterizadas pelo 
controle do indivíduo sobre os aspectos de sua carreira, que é dinâmica e flexível (BENDASSOLLI; WOOD JR., 2010); (3) as carreiras proteanas, que enfatizam a satisfação pessoal do indivíduo (HALL, 2002); e as carreiras multidirecionais, nas quais ser bem-sucedido não significa crescer hierarquicamente, mas trilhar diferentes caminhos ao longo da vida profissional (ROSA; ZAMPLER; STEFANO, 2017). Dentre as dimensões estudadas, destacam-se as transições de carreira (KILIMNIK; VISENTIN, 2014), as âncoras (SCHEIN, 1993), as relações entre trabalho e vida pessoal (MEIJERS, 1998), as metáforas de carreira (INKSON, 2004), as identidades e as redes de relacionamento (IBARRA; DESHPANDE, 2007).

Como fruto de nossa análise, podemos entender as pesquisas sobre carreira e sua gestão a partir de dois eixos: um mais descritivo e outro mais axiológico. O eixo descritivo refere-se a um conjunto de pesquisas que buscam compreender o processo de carreira, descrevendo suas transições, seus significados, suas metáforas, mas sem se preocuparem com uma a intervenção ou gestão da carreira feita pelos indivíduos ou pelas organizações. O eixo axiológico concentra pesquisas que privilegiam a produção de um conhecimento direcionado para a ação e para a preocupação com aspectos de gestão. Ou seja, as pesquisas desse eixo buscam produzir conhecimento que possa ser utilizado pelos indivíduos na gestão de suas próprias carreiras ou na gestão da carreira de outros indivíduos. Esses indivíduos podem ser artistas ou gestores de artistas.

\section{Carreiras como compreensão de um processo:}

a dimensão da descrição da carreira

O conjunto de pesquisas focadas na descrição do processo de carreira cresceu bastante ao longo dos anos. Este se consolidou como um campo estudado sob múltiplas lentes que buscam, de maneira geral, compreender e explicar como a carreira de um indivíduo é construída e evolui, pelo planejamento e acompanhamento da organização ou pelo direcionamento estabelecido pela própria 
pessoa. Assim, torna-se comum analisar a carreira com uma visão de processo, deixando de lado a preocupação com sua gestão.

\section{Tipos e sentidos das carreiras}

Tradicionalmente, os estudos sobre carreiras estão voltados para o universo organizacional, focando o desenvolvimento profissional dentro do conceito de emprego e empregabilidade (ALVES, 2012). Nas carreiras tradicionais, a visão do sucesso está diretamente relacionada a fatores como reconhecimento, promoções e remunerações. O crescimento profissional de um indivíduo diz respeito à ascensão na hierarquia de uma organização ao longo da carreira.

A carreira proteana é um conceito que tem como objetivo principal a satisfação pessoal do indivíduo. Estando muito ligado à autonomia e à instabilidade, substitui as relações profissionais de longo prazo pelas de curto prazo (HALL; ZHU; YAN, 2002). Nesse contexto, o sucesso psicológico do indivíduo é a principal orientação de motivação e busca profissional, associado diretamente às esferas profissional, individual e familiar em um único contexto (ALVES, 2012). O conceito de carreiras sem fronteiras, surgido em meados da década de 1990, caracteriza-se pela independência do indivíduo no controle da sua carreira, sua mobilidade profissional, aprendizado e desenvolvimento (ALVES, 2012). Segundo essa abordagem, o trabalho é dinâmico e flexível em termos de locais e horários, podendo ser oferecido em mais de uma organização. Não há estabilidade e o desenvolvimento profissional é horizontal. Nesse contexto, o indivíduo passa por diversas empresas e posições hierárquicas ao longo de sua carreira.

As carreiras multidirecionais vão de encontro às carreiras tradicionais, por serem flexíveis, dinâmicas e abertas a diferentes direções e possibilidades, inclusive de mudança total nos objetivos e metas do profissional. Ser bem-sucedido, nas carreiras multidirecionais, não significa apenas subir na hierarquia, pois existem outros caminhos a serem trilhados (ROSA; ZAMPLER; STEFANO, 2017). 
Além disso, outros estudos trabalham com a pesquisa de carreira, tomando como referência o conceito de metáforas (INKSON, 2004, 2007). Por exemplo, nove metáforas-chave podem agir como estruturas para muitas teorias de carreira, o que gera questões específicas. As metáforas-chave propostas por Inkson (2004) são as carreiras como herança, como construção, como ajuste, como ciclo, como jornada, como encontros e relações, como papeis, como recurso e como história. A metáfora limita o pensamento profissional a estereótipos poderosos, mas amplia as visões através da consideração de alternativas e da criação de novas metáforas.

\section{Principais dimensões de estudo da carreira}

Diversas dimensões da carreira têm sido estudadas ao longo dos anos. Algumas tiveram mais destaque, seja na quantidade de trabalhos realizados, seja na relevância real de cada tema. Uma dimensão que tem sido bastante estudada há décadas é a transição de carreiras. O trabalho "Career transitions: varieties and commonalities", de Meryl Reis Louis (1980) é o precursor (KILIMNIK; VISENTIN, 2014). A transição caracteriza-se por ser o período em que um indivíduo está trocando de papeis ou está em busca de um objetivo diferente. Ela seria uma etapa do desenvolvimento profissional e socioprofissional, podendo ser involuntária (demissão, divórcio) ou voluntária (retorno aos estudos, após um tempo afastado) (KILIMNIK; VISENTIN, 2014).

O termo âncora de carreira (inclinação profissional) é usado para designar a autoimagem de uma pessoa em relação aos seus talentos, habilidades, motivos, necessidades, atitudes e valores no que diz respeito ao trabalho (SCHEIN, 1993). Essa autoimagem orienta e influencia a carreira do indivíduo, de maneira que ele não desistirá da sua escolha profissional, ainda que seja forçado a desempenhar outra função (SILVA, 2010). Schein (1996) propõe oito âncoras: competência técnica/funcional, competência gerencial geral, autonomia/independência, segurança/estabilidade, 
criatividade empreendedora, serviço/dedicação a uma causa, puro desafio e estilo de vida.

Diversas pesquisas abordam a necessidade de aquisição de habilidades específicas, visando atingir uma identidade de carreira. Essas habilidades são um conjunto de significados que combinam motivação, interesses e competências com papeis de carreira de um indivíduo (MEIJERS, 1998). O posicionamento da identidade está diretamente ligado ao histórico particular, contextos culturais e interacionais em que o indivíduo está inserido (LAPOINTE, 2010). Outras pesquisas tratam da necessidade de mudança de identidade com o objetivo de adequar-se às realidades organizacionais a que está submetido, abordando as mudanças positivas de identidade e suas potenciais implicações na criatividade do indivíduo (HALL, 2002; IBARRA, 2003; IBARRA; BARBULESCU, 2010).

Redes de relacionamento constituem outra dimensão bastante considerada nas pesquisas. Elas são vistas como fundamentais para a construção da carreira, sendo estudadas a partir da maneira com a qual as afetam. São os recursos sociais a partir dos quais as carreiras se moldam (IBARRA; DESHPANDE, 2007). O termo "capital social" é usado para descrever a importância das redes de relacionamento como recurso para compreender as mudanças nas formas de organização (TEMPEST; MCKINLEY; STARKEY, 2004). É fundamental que o indivíduo cultive uma rede de relações, visando a construção de uma imagem positiva no mercado de trabalho, sendo um empreendedor de si mesmo, uma marca (BENDASSOLLI; WOOD JR., 2010).

\section{Carreiras como ação sobre um processo: \\ a dimensão da gestão da carreira}

A análise das pesquisas existentes no campo das carreiras demonstrou uma forte tendência a abordar o tema de um ponto de vista descritivo, contemplativo ou retrospectivo. Com efeito, a maior parte dos trabalhos se preocupa em teorizar ou interpretar os componentes ou dimensões da carreira. Quando o objetivo é pensar 
em estratégias ativas que justifiquem a utilização dos termos gestão ou administração, são escassas as pesquisas existentes. Essa lacuna é bastante recorrente nas pesquisas encontradas, embora seja possível identificar em alguns campos poucos trabalhos que busquem analisar de maneira dinâmica as estratégias possíveis de aplicação nas carreiras.

Quando se fala de carreiras artísticas, alguns autores se preocupam com esse aspecto, como na utilização das mídias sociais e de novas tecnologias de gestão por artistas independentes na construção da carreira (AMARAL; TARGA, 2017; HAYNES; MARSHALL, 2017). Há também pesquisas que procuram demonstrar os aprendizados que administradores podem obter através da experiência de artistas e atletas (OLIVEIRA, 2011). Essas pesquisas trazem soluções para auxiliar os gestores de carreiras a encontrar caminhos para melhor gerir suas trajetórias profissionais.

Em outras áreas essa realidade se mantém, mas, ainda assim, é possível encontrar alguns trabalhos que tenham a perspectiva axiológica como foco. Há pesquisas que apresentam a elaboração de planos de carreira, por parte das organizações, como instrumento efetivo de gestão integrada de pessoas (DIAS; OSWALDO, 2012). Outras pesquisas sugerem o empreendedorismo tecnológico como opção de carreira na aposentadoria (FREIRE et al., 2014). Embora seja possível encontrar pesquisas que utilizem da perspectiva axiológica para o desenvolvimento de carreiras, elas são, ainda, muito pouco expressivas e representativas na produção acadêmica.

\section{GESTÃO, CARREIRA E TRABALHO CRIATIVO: PESQUISAS EXISTENTES}

as carreiras criativas não estão necessariamente ligadas à carreira nas artes (música, teatro, dança, artes plásticas etc.). Na verdade, elas dizem respeito a pesquisas que versam sobre a mobilização da criatividade no dia a dia e no escopo da carreira, seja ela em 
organizações artísticas ou não. Elas incluem, por exemplo, trabalhos em agências publicitárias, que se utilizam da criatividade para a criação das suas peças (MCLEOD; O'DONOHOE; TOWNLEY, 2009). Dessa maneira as carreiras artísticas estão inseridas no constructo das carreiras criativas, por também estarem ligadas à necessidade da criatividade no seu escopo profissional.

\section{A evolução dos estudos sobre gestão, carreira e trabalho criativo}

Estudos que abordam as carreiras criativas não são um fenômeno recente. É possível encontrar registros deste tipo de trabalho desde o início da década de 1980, no livro Careers and creativity, que relaciona carreiras e criatividade nas forças sociais das artes (WHITE, 1980). No contexto da gestão, ainda nessa década (em 1985) foi estabelecido o pressuposto da indústria cultural que define a convergência entre artes, negócios e tecnologia (BENDASSOLLI et al., 2009). Ao longo dos anos, uma série de novos estudos relacionaram conceitos de gestão e carreiras com o trabalho dos profissionais criativos.

Apesar do constante crescimento na quantidade de trabalhos nesse campo, é a partir dos anos 2000 que a pesquisa acadêmica nas indústrias criativas ganha corpo. Se avolumam as pesquisas e os conteúdos estudados. É nesse momento que podemos perceber uma fragmentação de temáticas, que vão desde as várias áreas do campo (por exemplo música, teatro, cinema), quanto de temáticas como os riscos da carreira criativa e o trabalho criativo (MENGER, 1999; TEMPEST; MCKINLAY; STARKEY, 2004). Na produção acadêmica brasileira observa-se esse movimento de maneira ainda mais tardia, a partir do final da década de 2000. Apesar disso, diversos estudos mostram-se relevantes para o campo, analisando tanto a gestão das carreiras como relacionando-as com as principais teorias do campo (BENDASSOLLI; ANDRADE, 2011; TAVARES; PIMENTA; BALASSIANO, 2010).

Assim como nas pesquisas gerais sobre carreiras, no campo específico das carreiras criativas há uma tendência à realização de 
pesquisas predominantemente descritivas, em detrimento das axiológicas. Percebe-se claramente uma ênfase na análise de situações e descrição de casos visando relacioná-los às principais teorias e sentidos de carreiras já estabelecidos na produção acadêmica sobre carreiras. Apesar disso, alguns temas se destacam nos estudos sobre carreiras criativas.

\section{Principais dimensões de estudo da carreira criativa}

Muitas pesquisas abordam o processo de construção, desenvolvimento e manutenção da carreira de um artista. Embora casos e perspectivas diferentes sejam abordados nessas pesquisas, existem alguns tópicos em comum que são estudados ou citados na maioria delas. Por exemplo, podemos destacar os riscos e as incertezas inerentes à carreira artística, a relação entre amadorismo e profissionalismo e as tensões na relação entre arte e gestão do trabalho criativo. Um tema abordado com frequência em pesquisas sobre carreiras artísticas é a incerteza do mercado de trabalho, em que há constante aumento do emprego e do desemprego, como uma condição de inovação, auto realização e atração (MENGER, 1999). Menger analisa quatro questões principais que implicam diretamente nas carreiras artísticas: o status nos padrões de emprego, as razões da escolha ocupacional, a diversificação do risco ocupacional e o excesso na oferta de artistas. A alta atratividade das ocupações artísticas deve ser equilibrada com o risco de falha e de uma profissionalização malsucedida, transformando empregos não rotineiros em empreendimentos efềmeros (BARLEY, 1989; MENGER, 1999; DUARTE; SILVA, 2013).

A construção das carreiras num ambiente de forças contraditórias, originárias dos laços entre cultura e economia, é analisada por meio da relação entre dois paradoxos: amadorismo-profissionalismo e valorização extrínseca-intrínseca do trabalho. Bendassolli e Wood Jr. (2010) discutem esses paradoxos a partir de entrevistas com artistas e profissionais atuantes nas indústrias criativas, visando contribuir para o entendimento das carreiras sem fronteiras. 
Seguindo um caminho similar, pode-se analisar a carreira artística além da noção de uma trajetória individual, enfocando a compreensão de como duas pessoas (um artista e o seu representante) podem sustentar o curso de uma carreira. Essa compreensão suscita, ainda, a definição de carreiras "simbióticas". É o que acontece na análise das tensões existentes nessa relação entre a gestão da carreira e a arte, no contexto da relação do cineasta espanhol Pedro Almodóvar com o seu irmão e produtor executivo Agustín Almodóvar (ALVAREZ; SVEJENOVA, 2002).

Há pesquisas que focam a carreira artística sob a ótica das principais teorias de carreira. Assim, analisa-se as configurações e os desdobramentos da carreira de artistas, visando a compreensão dos pontos específicos que convergem com as teorias tradicionais de carreira proteana e sem fronteiras (ALVES, 2012). Os estudos de carreira sem fronteiras se desenvolvem, ainda, através de um estudo de caso da trajetória de um indivíduo criativo comprometido com o objetivo de alcançar uma identidade/imagem distinta e autêntica em relação ao tempo e ao público (SVEJENOVA, 2005).

A trajetória artística está diretamente relacionada com as estruturas dos campos de carreira. Por esse motivo demonstra-se, a partir de biografias de músicos do jazz, como o caminho dos artistas é afetado por mudanças estruturais ocorridas nesses campos (KIRSCHBAUM, 2007). Com efeito o conceito de identidade torna-se central, uma vez que ele gera e energiza as artes, tanto para grupos quanto para indivíduos. A produção artística é estimulada e sustentada por um mundo da arte: é moldada sob o comprometimento de e da audiência, seja na identidade individual ou na de grupos sociais (FAULKNER, 2003; FAULKNER; ANDERSON, 2003; WHITE, 1980). 


\section{GESTÃO DE CARREIRAS CRIATIVAS:}

\section{PERSPECTIVAS PARA O FUTURO DA PESQUISA}

Constatamos que os estudos de carreiras em geral passam por diversas transformações ao longo dos anos. Com as carreiras criativas não tem sido diferente, especialmente com as constantes mudanças políticas, sociais e tecnológicas (MAUDONNET, 2015). Essas transformações inauguram frentes de pesquisa significativas, com valor tanto para renovar as pesquisas acadêmicas como para fortalecer a prática dos profissionais das organizações e indústrias criativas. A análise das pesquisas existentes nos conduz a elaborar e propor quatro tipos de perspectivas em gestão de carreiras criativas: axiológica, tecnológica, coletiva e social. Essas perspectivas são orientações para pesquisas futuras na área de gestão de carreiras criativas.

Na perspectiva axiológica, o enfoque da pesquisa recai na construção de conhecimentos sobre gestão de carreiras que permitam aos criativos e seus gestores melhor atuação no planejamento e na ação durante a carreira (gestão de carreiras voltada para a ação). Na perspectiva tecnológica, a preocupação dos pesquisadores se volta para considerar como as mudanças tecnológicas afetam o contexto dessa carreira. Na perspectiva coletiva, as pesquisas se orientam para pensar a carreira como uma gestão de grupo de criativos. A perspectiva social privilegia uma visão do indivíduo criativo e de sua carreira orientados para valores comunitários, associativos e solidários.

\section{A perspectiva axiológica na gestão de carreiras criativas.}

Esta perspectiva procura construir conhecimentos sobre a gestão de carreiras que permitam mais atuação de criativos e seus gestores no planejamento e na ação durante a carreira. Ela é voltada para a ação, no sentido prático da gestão, não se resumindo à descrição de um fenômeno ou de uma teoria de carreira. Pesquisas dentro dessa perspectiva analisam as decisões e implicações da gestão, 
buscando indicar caminhos efetivos no processo de uma carreira criativa (PINHEIRO et al., 2016). Dessa maneira, há uma busca por conceitos que possibilitem a compreensão da carreira a partir de um contexto de planejamento, tomada de decisão e gestão, tendo a ação como sua principal âncora de conhecimento (AMARAL; TARGA, 2017). Pesquisadores podem mobilizar teorias baseadas em prática (FELDMAN; WORLINE, 2016; GOLSORKHI et al., 2015; NICOLINI, 2013; VAARA; WHITTINGTON, 2012) e em processos (LANGLEY; TSOUKAS, 2017) para entender e propor novas produções acadêmicas sobre o processo, a estratégia e a prática da gestão de carreiras criativas.

\section{A perspectiva tecnológica na gestão de carreiras criativas.}

A perspectiva tecnológica leva em consideração como as constantes transformações tecnológicas afetam e se articulam com os contextos da carreira. Há uma obsessão com as mídias eletrônicas por parte da geração X, para quem o $e$-business oferece grandes desafios e oportunidades de novos tipos de trabalho (BARUCH, 2004). Esse diálogo entre o trabalho criativo e as novas tecnologias pode levar a grandes benefícios em vários aspectos, como a sua incorporação em serviços de venda de ingressos, divulgação de trabalhos, estabelecimento e manutenção de redes de relacionamento com pares e público consumidor. Por isso é importante para os profissionais das indústrias criativas estarem constantemente atentos a essas mudanças para que possam com elas lidar de maneira criativa e adequada (MAUDONNET, 2015). O enfoque nas transformações tecnológicas podem abrir caminho para a descobertas de novas dimensões e dinâmicas que animam e conformam as carreiras e suas práticas de gestão.

A perspectiva coletiva na gestão de carreiras criativas.

Essa perspectiva pensa a carreira como uma gestão de grupo de criativos, expandindo o conceito de carreira individual para além de uma pessoa. Ela faz parte de um movimento crescente que enxerga 
a liderança em termos da colaboração entre duas ou mais pessoas (CREVANI; LINDGREN; PACKENDORFF, 2007). Essa perspectiva implica pluralidade, que é a influência de múltiplos líderes em situações organizacionais específicas (DENIS; LANGLEY; SERGI, 2012). Pode caracterizar, por exemplo, a gestão de uma banda musical ou de uma equipe de roteiristas de series televisivas, na qual não é a carreira de um único indivíduo que está sendo gerida, mas a de um grupo de pessoas. Apesar de esse ser, talvez, o exemplo mais claro da perspectiva coletiva, diversos contextos criativos podem se enquadrar nela, desde que representem uma coletividade como valor primordial do processo organizativo e criativo. Pesquisas futuras poderão rever a forma de pensar e praticar a carreira e sua gestão como uma prática coletiva. Ou seja, a visão da carreira como atividade coletiva pode modificar drasticamente a visão vigente que se calca predominantemente no indivíduo e em sua trajetória de vida. Então, como seria pensar a carreira e sua gestão a partir da trajetória de vida e de práticas de um coletivo?

\section{A perspectiva social na gestão de carreiras criativas.}

A perspectiva social de carreiras criativas privilegia a orientação do criativo para valores comunitários, associativos e solidários (HALL, 2000). Nesse contexto o indivíduo não tem como objetivo principal de sua carreira a conquista de sucesso e/ou a obtenção de altos lucros com o seu trabalho. Ela está relacionada ao pertencimento a uma cultura étnica, racial, linguística, religiosa, regional ou nacional, que forma o indivíduo e direciona a sua carreira em prol da comunidade em que vive (HALL, 1999). Essa realidade visa a construção de carreiras sob visões comerciais comunitárias e sem fins lucrativos, priorizando o desenvolvimento de um grupo social, ou da comunidade em que está inserido (MARKUSEN et al., 2006). Nessa abordagem da carreira criativa, diversos outros setores da sociedade podem se inserir e contribuir para o desenvolvimento desse setor. Essa perspectiva abre novas avenidas de pesquisa para repensar um dos pressupostos básicos da gestão de 
carreiras nas indústrias criativas: a carreira é energizada pelas experiências artísticas (arte) e pelas condições econômicas advindas da arte (comércio). No entanto, as dimensões sociais também podem ser fator motivador e mobilizador para estruturar uma carreira que tem a criatividade como eixo. Novas pesquisas nessa linha também podem contribuir muito para gerar outras visões sobre as carreiras criativas e suas formas singulares de gestão.

\section{CONCLUSÕES}

Este artigo promoveu um entendimento sobre a relação existente entre as perspectivas descritiva e axiológica nos estudos sobre carreiras e, mais especificamente, sobre carreiras artísticas. A revisão de pesquisas publicadas permitiu identificar e explicar que grande parte dos trabalhos trata das carreiras através de uma visão descritiva, focada nas teorias, seus conceitos, elementos e características. Assim, observa-se uma lacuna significativa no que diz respeito a pesquisas que promovam uma perspectiva pautada pela prática, por processos estratégias de ação para pensar a gestão de carreiras criativas.

Os principais temas identificados nas pesquisas sobre carreira criativa estão ligados aos riscos e incertezas inerentes desse campo de trabalho e aos dilemas entre arte-gestão. Nesse setor há uma grande instabilidade profissional, com a constante abertura e fechamento de postos de trabalho, numa lógica de gestão por projetos. Com isso, não há espaço para muita acomodação por parte dos profissionais, uma vez que há um alto risco de ficarem desempregados. Além disso, é necessário encontrar formas de conciliar os aspectos artísticos com os de gestão.

Existe ainda uma quantidade relevante de trabalhos que associam as carreiras artísticas às principais teorias de carreira. As mais abordadas são as carreiras sem fronteiras, as âncoras e as metáforas de carreira, que são bastante discutidas num contexto geral das pesquisas, não se restringindo ao universo criativo e artístico. 
Ainda que muito estudadas, são também analisadas sob o viés da perspectiva descritiva, deixando pouco conhecimento sobre questões voltadas para a ação.

Como forma de contribuir para o avanço da pesquisa sobre carreiras criativas e artísticas, esta pesquisa desenvolve, discute e propõe quatro perspectivas para o estudo futuro sobre gestão de carreiras criativas: a axiológica, a tecnológica, a coletiva e a social. São orientações para alimentar a discussão de caminhos a serem adotados, investigados e criticados por pesquisadores de carreiras criativas. Indiretamente, ao refletirmos sobre questões de gestão de carreiras criativas estamos refletindo sobre uma dimensão fundamental para o desenvolvimento da economia criativa. Na prática profissional, nossa pesquisa pode auxiliar os artistas, aproximando-os da produção acadêmica que informa suas práticas, permitindo-os vislumbrar percursos e recursos para um melhor planejamento e desenvolvimento das suas carreiras.

\section{REFERÊNCIAS}

ADAMSON, S. J.; DOHERTY, N.; VINEY, C. The meanings of career revisited: implications for theory and practice. British Journal of Management, London, v. 9, n. 4, p. 251-259, dez. 1998.

ALVAREZ, J. L.; SVEJENOVA, S. Symbiotic careers in movie making: Pedro and Agustín Almodovar. In: PEIPERL, M.; ARTHUT, M.; ANAND,

N. Career creativity: explorations in the remaking of work. New York: Oxford University Press, 2002. p. 183-208.

ALVES, A. B. Um estudo sobre a jornada profissional do artista e as teorias de carreira. Pensamento \& Realidade, São Paulo, v. 27, n. 4, p. 71-90, 2012.

AMARAL, A.; TARGA, P. V. Estudo da construção de carreira internacional aplicando os pilares do framework Scrum. Revista de Tecnologia Aplicada, São Paulo, v. 6, n. 3, p. 3-14, 2017.

ARTHUR, M. B.; HALL, D. T.; LAWRENCE, B. S. (ed.). Handbook of career theory. New York: Cambridge University Press, 1989. 
BARLEY, S. R. Careers, identity, and institutions: the legacy of the Chicago School of Sociology. In: ARTHUR, M. B.; HALL, D. T.;

LAWRENCE, B. S. Handbook of Career Theory. New York: Cambridge University Press, 1989. p. 41-65.

BARUCH, Y. Managing careers: theory and practice. London: Pearson, 2004.

BENDASSOLLI, P. F.; ANDRADE, J. E. B. Significado do trabalho nas indústrias criativas. Revista de Administração de Empresas, São Paulo, v. 51, n. 2, p. 143-159, mar./abr. 2011.

BENDASSOLLI, P. F.; WOOD JR., T. O Paradoxo de Mozart: carreiras nas indústrias criativas. OESS, Salvador, v. 17, n. 53, p. 259-277, abr./jun. 2010.

BENDASSOLLI, P. F.; WOOD JR., T.; KIRSCHBAUM, G.; CUNHA, M. P. Indústrias criativas: definição, limites e possibilidades. Revista de Administração de Empresas, São Paulo, v. 49, n. 1, p. 10-18, jan./mar. 2009.

COLLIN, A. The meanings of career. In: GUNZ, H.; PEIPERL, M.

Handbook of Career Studies. Thousand Oaks: Sage, 2007. p. 558-565.

CREVANI, L.; LINDGREN, M.; PACKENDORFF, J. Shared leadership: a postheroic perspective on leadership as a collective construction. International Journal of Leadership Studies, Virginia Beach, v. 3, n. 1, p. 40-67, 2007.

DENIS, J. L.; LANGLEY, A.; SERGI, V. Leadership in the Plural. The Academy of Management Annuals, Briarcliff Manor, v. 6, n. 1, p. 211283, jun. 2012.

DIAS, E. A. ; OSWALDO, Y. C. Plano de carreira como instrumento efetivo de gestão integrada de pessoas : relato de consultoria em administração pública. Caderno Profissional de Administração, Piracicaba, v. 2, n. 2, 2012.

DUARTE, M. F.; SILVA, A. L. A experimentação do risco na carreira criativa: o caso de mestres da cultura do artesanato cearense. Revista Eletrônica de Ciência Administrativa, Campo Largo, v. 12, n. 2, p. $22-$ 38, maio/ago. 2013.

FAULKNER, R. R. Music on Demand: composers and careers in the Hollywood Filme Industry. New Jersey: Transaction, 2003. 
FAULKNER, R. R.; ANDERSON, A. B. Short-term projects and emergent careers: evidence from Hollywood. The American Journal of Sociology, Chicago, v. 92, n. 4, p. 879-909, 1987.

FELDMAN, M.; WORLINE, M. The practicality of practice theory. Academy of Management Learning $\mathcal{E}$ Education, Briarcliff Manor, v. 15, n. 2, p. 304-324, 2016.

FREIRE, J. R. S.; SANTOS, I. C.; SANTOS, S. A.; CASTRO, A. D. M.; SOARES, D. A. S. R. Empreendedorismo tecnológico como opção carreira na aposentadoria. Revista de Empreendedorismo e Gestão de Pequenas Empresas, São Paulo, v. 3, n. 2, p. 94-119, 2014.

GOLSORKHI, D.; ROULEAU, L.; SEIDL, D.; VAARA, E. (ed.). Cambridge Handbook of Strategy as Practice. Cambridge: Cambridge University Press, 2015.

HALL, D. T.; ZHU, G.; YAN, A. Career creativity as protean identity transformation. In: PEIPERL, M.; ARTHUT, M.; ANAND, N. Career creativity: explorations in the remaking of work. New York: Oxford University Press, 2002. p. 159-180.

HALL, S. A identidade cultural na pós-modernidade. Rio de Janeiro: DP\&A, 2000.

HALL, S. A identidade cultural na pós-modernidade. Tradução Tomaz Tadeu da Silva e Guaracira Lopes Louro. 3 ed. Rio de Janeiro: DP\&A, 1999.

HAYNES, J.; MARSHALL, L. Beats and tweets: social media in the careers of independent musicians. New Media \& Society, Thousand Oaks, v. 20, n. 5, p. 1-21, 2017.

IBARRA, H. Working identity. Brighton: Harvard Business School Press, 2003.

IBARRA, H.; BARBULESCU, R. Identity as narrative: prevalence, effectiveness, and consequences of narrative identity work in macro work role transitions. Academy of Management Review, Briarcliff Manor, v. 35, n. 1, p. 135-154, 2010.

IBARRA, H.; DESHPANDE, P. H. Networks and identities: reciprocal influences on career processes and outcomes. In: GUNZ, H.; PEIPERL, M. Handbook of career studies. Thousand Oaks: Sage, 2007. p. 268-282. INKSON, K. Images of career: nine key metaphors. Journal of Vocational Behavior, Amsterdam, v. 65, p. 96-111, 2004. 
INKSON, K. Understanding careers: the metaphors of working life. Thousand Oaks: Sage, 2007.

KILIMNIK, Z. M.; VISENTIN, I. C. Evolução dos estudos internacionais sobre o tema carreira. Revista de Carreiras e Pessoas, São Paulo, v. 4, n. 2, p. 204-211, 2014.

KIRSCHBAUM, C. Careers in the right beat: US jazz musicians' typical and non-typical trajectories. Career Development International, Bingley, v. 12, n. 2, p. 187-201, 2007.

LANGLEY, A.; TSOUKAS, H. (ed.). The SAGE handbook of process organization studies. London: Sage, 2017.

LAPOINTE, K. Narrating career, positioning identity: career identity as a narrative practice. Journal of Vocational Behavior, Amsterdam, v. 77, n. 1, p. 1-9, 2010.

LOUIS, M. R. Career transitions: varieties and commonalities. Academy of Management Review, Briarcliff Manor, v. 5, n. 3, p. 329-340, 1980

MARKUSEN, A.; GILMORE, S.; JOHNSON, A.; LEVI, T.; MARTINEZ, A. Crossover: how artists build careers across commercial, nonprofit and community work. Menlo Park: The William and Flora Hewlett Foundation, 2006.

MAUDONNET, D. L.; JR., T. W. Estratégias de reorientação a carreira musical frente às mudanças tecnológicas e institucionais. In:

ENCONTRO DA ANPAD, 39., 2015, Belo Horizonte. Anais [...]. Maringá: Anpad, 2015.

MCLEOD, C.; O'DONOHOE, S.; TOWNLEY, B. The elephant in the room? Class an creative careers in British advertising agencies. Human Relations, Thousand Oaks, v. 62, n. 7, p. 1011-1039, 2009.

MEIJERS, F. The development of a career identity. International Journal for the Advancement of Counceling, [Msida], v. 20, p. 191-207, 1998.

MENGER, P. M. Artistic labor markets and careers. Annual Review of Sociology, Palo Alto, v. 25, p. 541-574, 1999.

NICOLINI, D. Practice theory, work, and organization: an introduction. New York: M. E. Sharpe, 2013.

OLIVEIRA, L. B. Carreiras "exóticas": o que administradores podem aprender com as vivências de artistas, atletas e outros profissionais. Revista de Carreiras e Pessoas, São Paulo, v. 1, n. 2, set./dez. 2011. 
PINHEIRO, C. M. P.; BARTH, M.; SILVA, A. C.; SCHOSLER, A. P.; Hey ho let's go, rock gaúcho: análise da gestão da banda Tequila Baby. Revista Gestão Organizacional, Chapecó, v. 9, n. 3, p. 36-50, set./dez., 2016.

ROSA, F. A. S.; ZAMPLER, M. A.; STEFANO, S. R. Tipos de carreira: análise da produção científica. Revista de Carreiras e Pessoas, São Paulo, v. 7, n. 1, p. 358-373, jan./abr. 2017.

SCHEIN, E. Career anchors: discovering your real values. Revised edition. San Francisco: Jossey Bass, 1993.

SILVA, R. O. Expressão artística popular e carreira empreendedora na indústria criativa cearense: os cordelistas. 2010. 122 f. Monografia (Graduação em Administração) - Faculdade de Economia, Administração, Atuária e Contabilidade, Universidade Federal do Ceará, Fortaleza, 2010.

SVEJENOVA, S. 'The Path with the Heart': creating the authentic career. Journal of Management Studies, Hoboken, v. 42, n. 5, p. 947-974, 2005.

TAVARES, E.; PIMENTA, R. C.; BALASSIANO, M. Carreira sem fronteiras: o exemplo da carreira no futebol. Revista do Mestrado em Administração e Desenvolvimento Empresarial da Universidade Estácio de Sá, Rio de Janeiro, ano 10, v. 14, n. 2, p. 57-74, maio/set. 2010.

TEMPEST, S.; MCKINLAY, A., STARKEY, K. Careering alone: careers and social capital in the financial services and television industries. Human Relations, Thousand Oaks, v. 57, n. 12, p. 1523-1545, 2004. VAARA, E.; WHITTINGTON, R. Strategy-as-practice: taking social practices seriously. Academy of Management Annals, Abingdon, v. 6, n. 1, p. 285-336, 2012.

WHITE, H. C. Careers and creativity: social forces in the arts. Boulder: Westview Press, 1980. 